\title{
Congo red, doxycycline, and HSP70 overexpression reduce aggregate formation and cell death in cell models of oculopharyngeal muscular dystrophy
}

\author{
Y P Bao, S Sarkar, E Uyama, D C Rubinsztein
}

J Med Genet 2004;41:47-51. doi: 10.1136/jmg.2003.014548

T he formation of intracellular amyloid-like inclusions by mutant proteins is a feature of two groups of codon reiteration diseases, for which there are currently no treatments. The first group that was described includes the nine known neurodegenerative conditions caused by polyglutamine (polyQ) repeat expansions resulting from CAG trinucleotide repeat mutations, exemplified by Huntington's disease (HD). ${ }^{1}$ HD is caused by a tract of more than 37 uninterrupted polyglutamines in exon 1 of the HD gene product, huntingtin. Genetic and transgenic studies are consistent with a model where expanded polyglutamines cause disease by conferring a novel toxic function on the disease proteins. ${ }^{1-3}$

The second type of codon reiteration mutation results in autosomal dominant oculopharyngeal muscular dystrophy (OPMD). ${ }^{4}$ OPMD is caused by the abnormal expansion of a $(\mathrm{GCG})_{\mathrm{n}}$ trinucleotide repeat in the coding region of the polyadenine binding protein 2 gene $(P A B P 2)$ : a $(G C G)_{6}$ repeat is expanded to $(G C G)_{8-13}$ in most patients. In some rare cases, insertion mutations such as $(\mathrm{GCG})_{6} \mathrm{GCA}(\mathrm{GCG})_{2}$, $(\mathrm{GCG})_{6} \mathrm{GCA}(\mathrm{GCG})_{3}$ and $(\mathrm{GCG})_{6}(\mathrm{GCA})_{3}(\mathrm{GCG})_{2}$ are seen. ${ }^{56}$ In $P A B P 2,(G C G)_{6}$ codes for the first six alanines in a homopolymeric stretch of 10 alanines. Thus, disease is associated with expansions of 12 or more uninterrupted alanines in this nuclear protein. OPMD is characterised by aggregates in muscle cell nuclei comprising mutant PABP2 as a major component. ${ }^{4-9}$

The role of inclusions in these diseases has been vigorously disputed. ${ }^{1}$ Nevertheless, strategies that target protein misfolding frequently reduce aggregate formation and cell death in parallel. In mammalian cell based models of both polyglutamine and polyalanine diseases, the mutant proteins are much more prone to aggregate formation than their wildtype counterparts and cause significantly more cell death. ${ }^{111}$ In such models, aggregate formation and cell death can be reduced by overexpressing yeast and bacteria derived chaperones that do not appear to protect against some other cell death pathways. ${ }^{11-13}$ A causal role for aggregation in cell death in tissue culture models of OPMD is supported by complementary data from our lab and Rouleau's group. ${ }^{11}{ }^{14}$ Rouleau and colleagues found that oligomerisation of PABP2 is mediated by two potential oligomerisation domains (ODs)—deletions in either of these domains inactivated oligomerisation of mutant PABP2 and also reduced the cell death caused by this protein. ${ }^{14}$

The similarities between polyglutamine diseases and OPMD have led us to explore whether strategies that protect against polyglutamine aggregation or toxicity are also effective in OPMD models. Our previous studies suggested that mammalian heat shock proteins might be able to play similar roles in both diseases. ${ }^{11}{ }^{15}$ Members of the HSP70 and HSP40 family members are recruited to polyQ inclusions in vivo and in cell models. ${ }^{11}{ }^{15-21}$ We have tested

\section{Key points}

- Intracellular amyloid-like inclusions formed by mutant proteins result from polyglutamine expansions in Huntington's disease (HD) and polyalanine expansions in polyadenine binding protein 2 (PABP2) in oculopharyngeal muscular dystrophy (OPMD).

- Here we show further parallels between these diseases and suggest therapeutic strategies for OPMD. Like polyglutamine diseases, HSP7O and HDJ-1 colocalised with PABP2 aggregates in OPMD patient muscle tissue and overexpression of HSP70 reduced mutant PABP2 aggregate formation. Aggregate formation and cytotoxicity in cell models of OPMD were reduced by Congo red or doxycycline.

- Our data highlight the therapeutic potential of these compounds in oculopharyngeal muscular dystrophy.

if this is the case in OPMD patients, as we had previously shown that this occurred in a cell model of OPMD. ${ }^{11}$ We have previously shown that HDJl, an HSP40 family member, reduced aggregate formation and cell death in cell models of HD and OPMD. ${ }^{11}{ }^{15}$ Since HDJl is a co-chaperone for HSP70, we have now tested if HSP70 chaperone is effective in cell models of OPMD, as it can be effective in HD. ${ }^{15}$

Since it may be possible to treat these diseases with compounds that reduce aggregate formation, we have been testing a number of anti-amyloid compounds in cell based models of OPMD (where no animal models have been published). We tested Congo red, as data from Ross and colleagues suggested that it blocked the conversion of mutant huntingtin protofibrils into mature fibrils ${ }^{22}$ and Sanchez et al showed that Congo red reduced aggregation and cell death in HD cell models. ${ }^{23}$ The latter study also reported that infusion of Congo red into an HD mouse model by the intraperitoneal and intracerebroventricular routes improved survival, weight loss, and motor function, compared with untreated mutant mice. ${ }^{23}$ These data provided important insights into the role of inclusions polyglutamine disease pathology and suggested that the beneficial effects of Congo red were due to its

Abbreviations: DAPI, 4', 6-diamidino-2-phenylindole; DMEM, Dulbecco's modified Eagle's medium; Dox, doxycycline hydrochloride; EGFP, enhanced green fluorescent protein; GFP, green fluorescent protein; HD, Huntington's disease; HSP, heat shock protein; OD, oligomerisation domain; OPMD, oculopharyngeal muscular dystrophy; $\mathrm{PABP} 2$, polyadenine binding protein 2; polyQ, polyglutamine 
anti-aggregate properties. Unfortunately, the therapeutic potential for Congo red in HD may be minimal, because of its very poor blood brain barrier permeability. ${ }^{24}$ On the other hand, brain penetrance would not be an issue for a muscle disease like OPMD. We also tested doxycycline as an antiaggregate compound, since previous studies had suggested that tetracyclines were anti-amyloidogenic. ${ }^{25}$

\section{MATERIALS AND METHODS \\ Cell culture and transfection}

African green monkey kidney (COS-7) cells were grown in Dulbecco's modified Eagle's medium (DMEM 5471) (Sigma) supplemented with $10 \%$ fetal bovine serum, 100 units $/ \mathrm{ml}$ penicillin/streptomycin, and $2 \mathrm{mM} \mathrm{L-glutamine} \mathrm{at} 37^{\circ} \mathrm{C}, 5 \%$ $\mathrm{CO}_{2}$. For transfection of plasmid DNA, cells were seeded on coverslips at $0.6-1 \times 10^{5}$ per well, in 6-well plates, the day before transfection. Cells were transfected with Lipofectamine (Life Technologies) according to the manufacturer's instructions. Constructs are described in refs 11 (PABP2) and 15 (HSP70).

\section{Compounds and treatment}

Congo red (Sigma) was dissolved in DMEM 5671(Sigma) with a stock concentration of $10 \mathrm{mg} / \mathrm{ml}$. Doxycycline hydrochloride (Dox) (Sigma) was dissolved in water with a stock concentration of $100 \mathrm{mg} / \mathrm{ml}$. All the stock solutions were sterilised through a filter with a $0.2 \mu \mathrm{M}$ pore diameter. The compounds were diluted to the required concentration in the cell culture medium immediately before use. At $24 \mathrm{~h}$ after transfection, the compounds were added to the cells at different concentrations. The cells were incubated with the compounds for another $24 \mathrm{~h}$ and then washed with $1 \times$ phosphate buffered saline, fixed in $4 \%$ paraformaldehyde for $20 \mathrm{~min}$, mounted in antifadent reagent supplemented with $3 \mu \mathrm{g} / \mathrm{ml}$ of $4^{\prime}$, 6-diamidino-2-phenylindole (DAPI) to allow visualisation of nuclear morphology.

\section{Western blotting analysis}

Cells were lysed with Laemmli buffer $(0.0625 \mathrm{M}$ Tris-HCl, pH 6.8, 2\% SDS, 5\% $\beta$-Mercaptoethanol, 10\% Glycerol, 0.01\% Bromophenol Blue). Lysates were subjected to SDS-polyacrylamide gel $(10 \%)$ electrophoresis and transferred to a nitrocellulose membrane (Amersham Pharmacia Biotech, UK). The membrane was incubated with mouse polyclonal anti-HSP70 (StressGene, 1:1000), mouse polyclonal antiHDJ-1 (StressGene, 1:1000) and rabbit anti-actin (Sigma, 1:2000), respectively. Blots were then incubated with peroxidase conjugated antimouse or antirabbit IgG antibody (Amersham Pharmacia Biotech, 1:1000). The proteins were detected using the enhanced chemiluminescence reagent (Amersham Phamacia Biotech). Protein loading was corrected by reprobing blots for actin.

\section{Immunohistochemistry}

Studies on human muscle samples were performed with the approval of ethics committees in Cambridge and Kumamoto. We have analysed frozen tissue sections from a muscle biopsy of the right sternohyoideus from an OPMD patient (female, 62 years old, with a 15 polyalanine expansion mutation in the PABP2 gene (genotype: $\left.(G C G)_{11} /(G C G)_{6}\right)$ ), the right gastrocnemius muscle from a patient (female, 61 years old, 15 polyalanines in PABP2; (genotype: $\left.(\mathrm{GCG})_{11} /(\mathrm{GCG})_{6}\right)$, the right deltoid muscle from a normal control ( 20 years old) and the right biceps muscle from a patient with dentatorubral pallidoluysian atrophy (non-OPMD disease control, male, 62 years old). The sections were fixed in $4 \%$ paraformaldehyde fixative for $10 \mathrm{~min}$ and then blocked with $5 \%$ horse serum for 1h. The colocalisation of endogenous PABP2 with HSP70, or PABP2 with HSP40 was detected by using the rabbit polyclonal anti-PABP2 antibody ${ }^{26}$ (1:200, kindly provided by Professor Elmar Wahle, Halle, Germany) together with the monoclonal mouse anti-HSP70 (1:200), or by using antiPABP2 antibody together with the monoclonal mouse antiHDJ-1 (1:200). The sections were then incubated with the mixture of antirabbit Texas red conjugated goat IgG antibody (Molecular probes, USA) and antimouse FITC conjugated goat IgG antibody (Alexa Fluor G488, Molecular probes, USA).

\section{Confocal microscopy}

Fluorescently labelled samples were analysed using the laser scanning microscope Zeiss LSM410 equipped with an argon ion laser (wavelength, $488 \mathrm{~nm}$ ) to excite FITC fluorescence, and a helium neon laser (wavelength, $543 \mathrm{~nm}$ ) to excite Texas red fluorescence. For double labelling experiments, images from the same focal plane were sequentially recorded in different channels and merged to confirm colocalisation.

\section{Measurement of aggregate formation and abnormal cell nuclei}

Cells were fixed with $4 \%$ paraformaldehyde at $72 \mathrm{~h}$ after transfection and counterstained with DAPI. Aggregate formation and nuclear morphology were assessed with a fluorescence microscope. Two hundred enhanced green fluorescent protein (EGFP) expressing cells were counted (with the observer blinded to the slide identity) across the centre region of the slides, to quantify all types of polyalanine aggregates in the cells. We assessed the proportions of PABP2-A17 expressing cells that contained one or more inclusions. We considered cells to have inclusions if the green fluorescent protein (GFP) was abnormally concentrated and differed from the nuclear speckled appearance typically seen with the normal PABP2-A10. Cells were considered dead if the DAPI-stained nuclei showed apoptotic morphology (fragmentation or pyknosis). Pyknotic nuclei are typically $<50 \%$ diameter of normal nuclei and show obvious increased DAPI intensity. We have demonstrated that these criteria are specific for cell death, as they show a very high correlation with propodium iodide staining in live cells. ${ }^{15}$

\section{Statistical analysis}

As we and others have described previously, ${ }^{10-13}$ pooled estimates for the changes in inclusion formation resulting from perturbations assessed in multiple experiments were calculated as odds ratios with $95 \%$ confidence intervals:

$$
\left(\begin{array}{c}
\% \text { cells expressing construct with inclusions } \\
\text { in perturbation conditions } \\
\% \text { cells expressing construct without } \\
\text { inclusions in perturbation conditions }
\end{array}\right)
$$

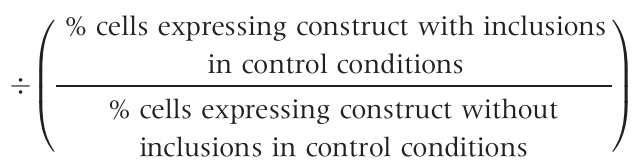

Odds ratios and $\mathrm{p}$ values were determined by unconditional logistical regression analysis using the general log/ linear analysis option of SPSS ver 6.1 software (SPSS, Chicago, USA). $\mathrm{p}<0.05$ was considered to be statistically significant.

\section{RESULTS}

To test if the intranuclear inclusions in OPMD patients sequester heat shock proteins (HSPs) in a manner similar to what we described in cell models, we used double staining 


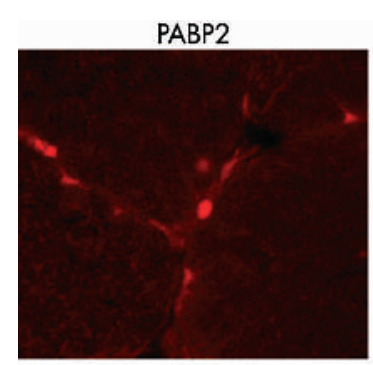

PABP2
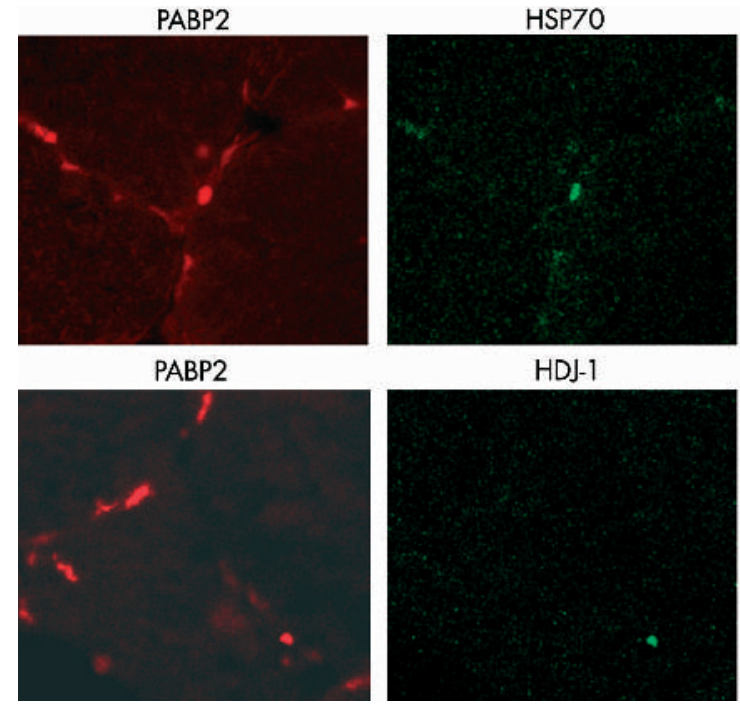

HDJ-1
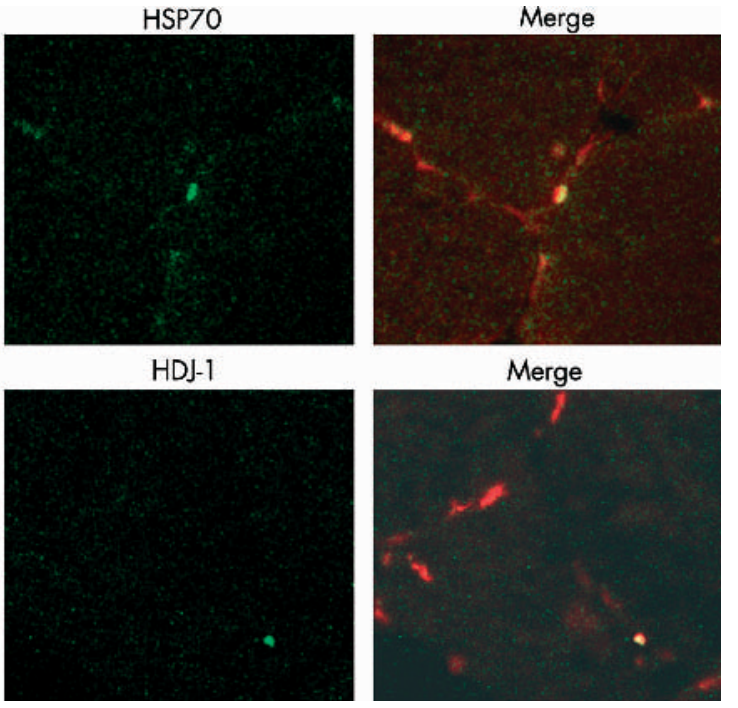

Merge

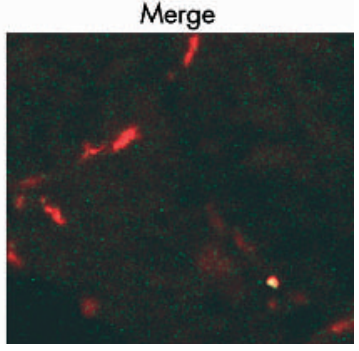

Figure 1 Colocalisation of HSP70 and HDJ-1 with nuclear PABP2 inclusions in muscle biopsies from OPMD patients. Frozen sections of muscle biopsies from OPMD patients were processed for immunohistochemistry. Texas red conjugated (red) second antibody was used to label PABP2 and FITC conjugated (green) secondary antibody was used to label HSP70 and HDJ-1. Colocalisation was confirmed by analysing images from the same focal plane sequentially recorded in different channels by confocal microscopy.

immunohistochemistry to allow simultaneous analysis of both mutant PABP2 and the relevant HSPs. Fig 1 shows colocalisation of HSP70 and HDJ-1 (HSP40 family) in inclusions in the DAPI stained nuclei of OPMD muscle. Similar findings were observed in samples from two OPMD patients. No colocalisation of these HSPs with PABP2 was seen in two control muscle samples (data not shown). The anti-PABP2 antibody we have used ${ }^{26}$ has been previously used to distinguish between cells with and without PABP2 aggregates. ${ }^{9}{ }^{14}$. The strong nuclear staining for the chaperones correlated strongly with the cells with nuclear aggregates (fig 1).

Previously, we showed that GFP tagged mutant PABP2 with 17 alanines (PABP2-A17) resulted in increased intranuclear aggregate formation and cell death, compared with otherwise identical constructs with 10 alanines ${ }^{11}$. HSP70 co-expression with GFP tagged mutant PABP2 with 17 alanines (PABP2-A17) significantly reduced the proportion of GFP positive cells with aggregates, compared with cells cotransfected with an empty vector control (pFlag-empty) (fig 2). HSP70 overexpression reduced the toxicity of mutant PABP2 in parallel with the reduction in aggregates (fig 2). Fig 2B shows that total HSP70 levels increase in cells transfected with HSP70, or in cells treated with sodium arsenite, which induces a heat shock response (as a positive control).

We considered Congo red and doxycycline as chemical chaperones with the potential to reduce mutant PABP2 aggregation and toxicity. COS-7 cells (the only cell model that has been reported to show aggregation and cell death as a readout for mutant OPMD toxicity) were transfected with GFP-tagged mutant PABP2 with 17 alanines (PABP2-A17). Twenty four hours after transfection, we added different concentrations of Congo red and doxycycline for the next $24 \mathrm{~h}$ and then assessed the proportions of GFP positive cells with aggregates and cell death (as scored by apoptotic nuclear morphology). We found that both Congo red and doxycycline reduced aggregation and cell death caused by mutant PABP2 (fig 3A). These effects were not caused by these compounds inducing raised levels of stress inducible HSPs, like HSP70 (fig 3B). While Congo red did not protect against cell death caused by incubating cells in staurosporine $(2.5 \mu \mathrm{M})$ or $\mathrm{H}_{2} \mathrm{O}_{2}(400 \mu \mathrm{M})^{11}$, protective effects were observed with doxycycline (fig 3C). In these experiments,

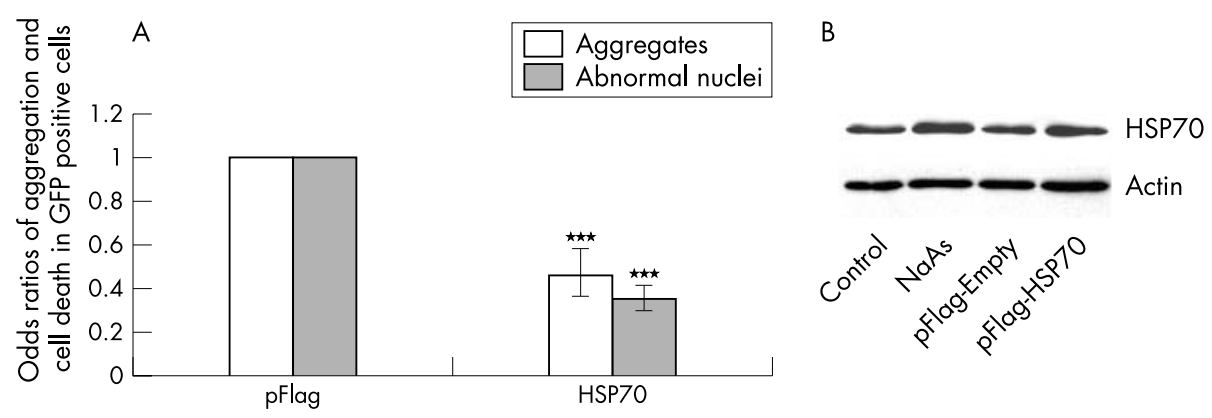

Figure 2 HSP70 overexpression suppresses aggregation of PABP2-A17 and its cytotoxicity. (A), PABP2-A17 (0.5 $\mu \mathrm{g})$ was cotransfected with an expression vector for HSP70 (pFlag-HSP70, $1.5 \mu \mathrm{g}$ ) or an empty vector (pFlag-empty, $1.5 \mu \mathrm{g}$ ). Cells were fixed and stained with DAPI $72 \mathrm{~h}$ after transfection. Aggregate formation and nuclear fragmentation/condensation were counted. The odds ratios were derived from $2-4$ independent experiments, each done in triplicate. The error bars represent the $95 \%$ confidence intervals for the odds ratios. ${ }^{*} \mathrm{p}<0.05 ;{ }^{* *} \mathrm{pp}<0.001 ;{ }^{* * *} \mathrm{p}<0.0001$; not significant, $p>0.05$. (B), Western blot showing expression of HSP7O in transfected COS-7 cells. COS-7 cells were either transfected with $2 \mu \mathrm{g}$ PABP2-A17, treated or non-treated with sodium arsenate $\left(\mathrm{NaAsO}_{2}, 50 \mu \mathrm{M}\right.$, treated for $\left.1 \mathrm{~h}\right)$ or cotransfected with PABP2-A17 (0.5 $\left.\mu \mathrm{g}\right)$ and pFlagHSP70 $(1.5 \mu \mathrm{g})$, PABP2-A17 and pFlag-empty $(1.5 \mu \mathrm{g})$. NaAsO 2 was used as a positive control to stimulate HSP70 expression. 

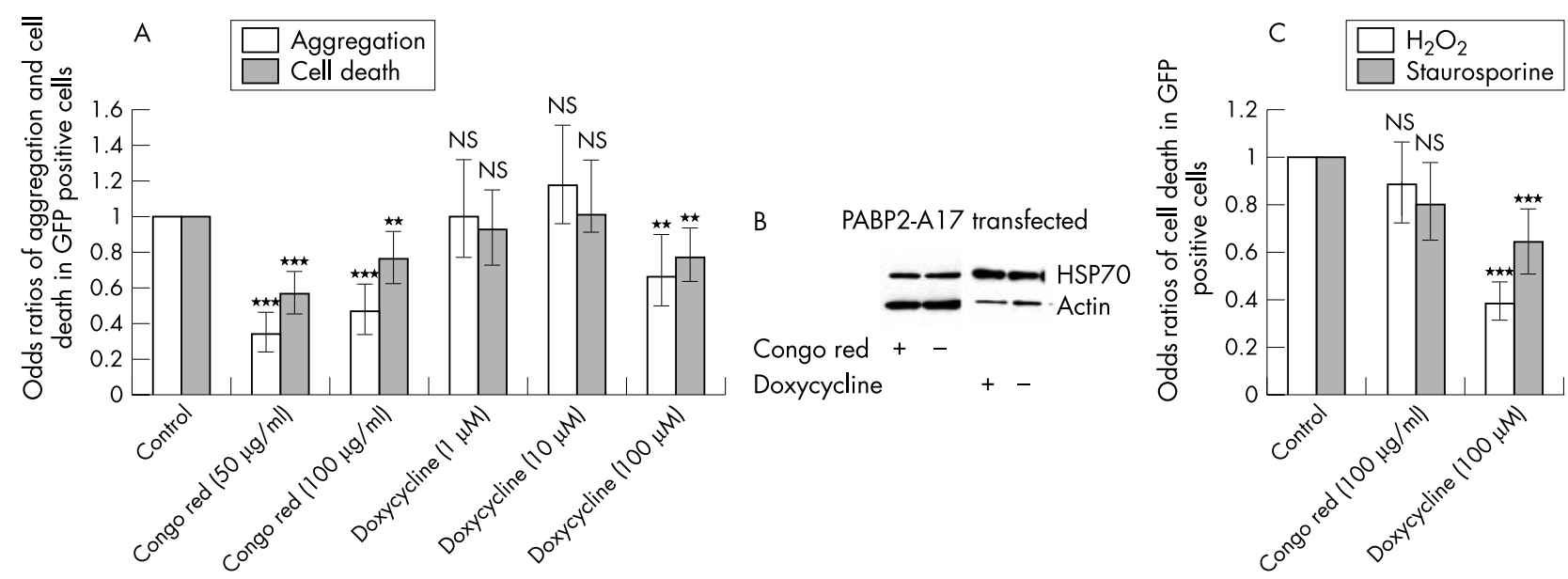

Figure 3 Congo red and doxycycline (Dox) reduce aggregation and cell death in cell models of OPMD and HD. (A) COS-7 cells were transfected with PABP2-A17. Congo red or Dox with different doses were added $24 \mathrm{~h}$ after transfection. Cells were incubated with the compounds for another $24 \mathrm{~h}$ and then fixed and stained with DAPI. The proportions of cells with aggregates and nuclear fragmentation or condensation were determined. The odds ratios were derived from 2-4 independent experiments, each done in triplicate. The error bars represent the $95 \%$ confidence intervals for the odds ratios. ${ }^{*} p<0.05 ;{ }^{* *} p<0.001$; ${ }^{* * *} p<0.0001$; not significant, $\mathrm{p}>0.05$. The $95 \%$ confidence intervals for $50 \mu \mathrm{g} / \mathrm{ml}$ and $100 \mu \mathrm{g} / \mathrm{ml}$ Congo red overlap, suggesting that there are no significant differences between these doses. (B) Congo red and Dox do not stimulate the expression of HSP70. COS7 cells were transfected with PABP2-A17. $100 \mu \mathrm{g} / \mathrm{ml}$ of Congo red or $100 \mu \mathrm{M}$ of Dox was added to the cells $24 \mathrm{~h}$ after transfection. Cells were harvested after another $24 \mathrm{~h}$, Western blotting was carried out, and the expression level of HSP7O was detected. (C) Effects of Congo red (100 $\mu \mathrm{g} / \mathrm{ml}$ ) and Dox $(100 \mu \mathrm{M})$ on cell death caused by pro-apoptotic agents. COS-7 cells were transfected with the vector pEGFP-Cl and the Congo red and doxycycline were added $24 \mathrm{~h}$ after transfection. After another $24 \mathrm{~h}$, either $\mathrm{H}_{2} \mathrm{O}_{2}$ or Staurosporine were added to the cells (for $4 \mathrm{~h}$ and $6 \mathrm{~h}$, respectively) before fixing the cells. Nuclear fragmentation and condensation were determined in GFP positive cells. The odds ratios were derived from 2-4 independent experiments, each done in triplicate. The error bars represent the $95 \%$ confidence intervals for the odds ratios. ${ }^{*} p<0.05 ;{ }^{* *} p<0.001 ;{ }^{* * *} p<0.0001$; not significant, $\mathrm{p}>0.05$.

cells were treated in the same protocol as described previously ${ }^{11}$, and staurosporine and $\mathrm{H}_{2} \mathrm{O}_{2}$ were added in the final $6 \mathrm{~h}$ and $4 \mathrm{~h}$, respectively, of the experiment.

\section{Discussion}

Both polyglutamine diseases like HD and polyalanine expansion mutations in PABP2 are associated with intracellular inclusions, whose appearance correlates with cell death in model systems. In this study we have extended the parallels between these different types of codon reiteration mutations by demonstrating HSP70 and HDJ-1 colocalisation in PABP2 inclusions in vivo, which has been previously observed in HD and related polyglutamine diseases ${ }^{15-21}$. The failure to detect colocalisation of these HSPs with PABP2 in wild-type samples or outside the nucleus in OPMD tissues is likely to be because the HSP preferentially associate with the aggregated protein and because PABP2 is predominantly nuclear in steady state. HSP70 overexpression resulted in a reduction of mutant $\mathrm{PABP} 2$ and $\mathrm{HD}$ exon $\mathrm{I}^{15}$ aggregation and cytotoxicity. While this paper was being written, Abu-Baker et al published data also showing colocalisation of HSP70 with OPMD aggregates and reduction of these aggregates with overexpression of this chaperone. ${ }^{27}$ Since HSP70 can directly protect against certain apoptotic pathways, for instance by inhibiting cytochrome c-mediated caspase activation, ${ }^{28}{ }^{29}$ it is important to be cautious about inferring a causal relationship between reduced aggregation and cell death in this context. Indeed, this cell death pathway is activated and contributes to the cytotoxicity in HD cell models. ${ }^{15}$

The reduction in aggregation and cell death mediated by Congo red and doxycycline against mutant PABP2 suggests that these compounds may have therapeutic potential, especially for OPMD. The concentrations that we have used are compatible with previous studies in HD models. We obtained significant reductions in aggregation and cell death caused by mutant PABP2 with $50 \mu \mathrm{g} / \mathrm{ml}(70 \mu \mathrm{M})$ Congo red, while Sanchez and colleagues reported reduction in their HD cell models with $100 \mu \mathrm{M} .{ }^{23}$ Recently, Smith et al reported that doxycycline reduced aggregation in a slice culture model of HD at $30 \mu \mathrm{M}^{30}$ while we observed protection in our OPMD model with $100 \mu \mathrm{M}$. Doxycycline appears to be protective by reducing aggregation and also by reducing susceptibility to cell death pathways induced by apoptotic inducers like staurosporine and $\mathrm{H}_{2} \mathrm{O}_{2}$, the latter effect compatible with the data of Chen et al who showed minocycline reduced caspase activation in a mouse model of HD. ${ }^{31}$ However, since tetracyclines are predicted to protect against apoptosis by inhibiting caspases and caspase 1 is interleukin- $1 \beta$-converting enzyme, the effects of tetracyclines may also be due to anti-inflammatory activity in certain in vivo disease models. While Congo red may have limited utility in HD due to its poor blood brain barrier permeability, ${ }^{24}$ it may be useful for diseases associated with aggregation outside the central nervous system, such as OPMD. Congo red appears to be a general amyloid protein ligand. ${ }^{31}$ In the case of HD, it blocks the conversion of protofibril to mature fibre formation in the aggregation process. ${ }^{22}$ Modelling studies reveal that Congo red is likely to break the continuity of the ordered structures of the $\beta$-sheets characteristic of polyalanine expansions, ${ }^{32}{ }^{33}$ thus providing a molecular explanation for the effect we observed with the mutant PABP2 protein. The parallel protection that Congo red affords against the cytotocity of expanded polyglutamines and polyalanines is consistent with the idea that abnormal protein aggregation and accumulation may be deleterious in all intracellular amyloidoses, irrespective of the primary mutation.

\section{ACKNOWLEDGEMENTS}

We thank Professor Elmar Wahle (Halle, Germany) for the supply of anti-PABP2 antibody.

\section{Authors' affiliations}

Y P Bao, S Sarkar, D C Rubinsztein, Department of Medical Genetics, Cambridge Institute for Medical Research, Wellcome/MRC Building, Addenbrooke's Hospital, Hills Road, Cambridge, CB2 2XY, United Kingdom 
E Uyama, Department of Neurology, Kumamoto University School of Medicine, 1-1-1-Honjo, Kumamoto, 860-0811, Japan

This work was funded by the Muscular Dystrophy Campaign (UK), the MRC (Programme grant to DCR and Professor Steve Brown) and Grantsin-Aid for Scientific Research (EU) for funding. We are grateful for a Wellcome Trust Senior Fellowship in Clinical Science (DCR) and a Gates Cambridge Scholarship (SS).

Correspondence to: D C Rubinsztein; dcr1000@cus.cam.ac.uk

Received 16 September 2003

In revised form 13 October 2003

Accepted 14 October 2003

\section{REFERENCES}

1 Rubinsztein DC. Lessons from animal models of Huntington's disease. Trends Genet, 2002; 18:202-9.

2 Lunkes A, Lindenberg KS, Ben-Haiem L, Weber C, Devys D,

Landwehrmeyer GB, Mandel JL, Trottier Y. Proteases acting on mutant huntingtin generate cleaved products that differentially build up cytoplasmic and nuclear inclusions. Mol Cell 2002; 10:259-69.

3 Wellington CL, Ellerby LM, Gutekunst CA, Rogers D, Warby S, Graham RK, Loubser O, van Raamsdonk J, Singaraja R, Yang YZ, Gafni J, Bredesen D, Hersch SM, Leavitt BR, Roy S, Nicholson DW, Hayden MR. Caspase cleavage of mutant huntingtin precedes neurodegeneration in Huntington's disease. J Neurosci 2002;22:7862-72.

4 Brais B, Bouchard JP, Xie YG, Rochefort DL, Chretien N, Tome FM, Lafreniere RG, Rommens JM, Uyama E, Nohira O, Blumen S, Korczyn AD, Heutink P, Mathieu J, Duranceau A, Codere F, Fardeau M, Rouleau GA, Korcyn AD. Short GCG expansions in the PABP2 gene cause oculopharyngeal muscular dystrophy. Nat Genet 1998;18:164-7.

5 Scacheri PC, Garcia C, Hebert R, Hoffman EP. Unique PABP2 mutations in "Cajuns" suggest multiple founders of oculopharyngeal muscular dystrophy in populations with French ancestry. Am J Med Genet 1999;86:477-81.

6 Nakamoto M, Nakano S, Kawashima S, Ihara M, Nishimura Y, Shinde A, Kakizuka A. Unequal crossing-over in unique PABP2 mutations in Japanese patients: a possible cause of oculopharyngeal muscular dystrophy. Arch Neurol 2002;59:474-7.

7 Tome FM, Chateau D, Helbling-Leclerc A, Fardeau M. Morphological changes in muscle fibers in oculopharyngeal muscular dystrophy. Neuromuscul Disord 1997;7(Suppl 1):S63-9.

8 Uyama E, Tsukahara T, Goto K, Kurano Y, Ogawa M, Kim YJ, Uchino M, Arahata K. Nuclear accumulation of expanded PABP2 gene product in oculopharyngeal muscular dystrophy. Muscle Nerve 2000;23:1549-54.

9 Calado A, Tome FM, Brais B, Rouleau GA, Kuhn U, Wahle E, CarmoFonseca $M$. Nuclear inclusions in oculopharyngeal muscular dystrophy consist of poly (A) binding protein 2 aggregates which sequester poly(A) RNA. Hum Mol Genet 2000;9:2321-8.

10 Wyttenbach A, Carmichael J, Swartz J, Furlong R, Narain Y, Rankin J, Rubinsztein DC. Effects of heat shock, heat shock protein 40 (HDJ-2), and proteasome inhibition on protein aggregation in cellular models of Huntington's disease. Proc Natl Acad Sci U S A 2000;97:2898-903.

11 Bao YP, Cook U, O'Donovan D, Uyama E, Rubinsztein DC. Mammalian, yeast, bacterial, and chemical chaperones reduce aggregate formation and death in a cell model of oculopharyngeal muscular dystrophy. J Biol Chem 2002;277:12263-9.

12 Carmichael J, Chatellier J, Woolfson A, Milstein C, Fersht AR, Rubinsztein DC. Bacterial and yeast chaperones reduce both aggregate formation and cell death in mammalian cell models of Huntington's disease. Proc Natl Acad Sci U S A 2000;97:9701-5.

13 Carmichael J, Vacher C, Rubinsztein DC. The bacterial chaperonin GroEL requires GroES to reduce aggregation and cell death in a COS-7 cell model of Huntington's disease. Neurosci Lett 2002;330:270-4.
14 Shanmugam V, Dion P, Rochefort D, Laganiere J, Brais B, Rouleau GA. PABP2 polyalanine tract expansion causes intranuclear inclusions in oculopharyngeal muscular dystrophy. Ann Neurol 2000;48:798-802.

15 Wyttenbach A, Sauvageot O, Carmichael J, Diaz-Latoud C, Arrigo AP, Rubinsztein DC. Heat shock protein 27 prevents cellular polyglutamine toxicity and suppresses the increase of reactive oxygen species caused by huntingtin. Hum Mol Genet 2002;11:1137-51.

16 Wyttenbach A, Swartz J, Kita H, Thykjaer T, Carmichael J, Bradley J, Brown R, Maxwell M, Schapira A, Orntoft TF, Kato K, Rubinsztein DC. Polyglutamine expansions cause decreased CRE-mediated transcription and early gene expression changes prior to cell death in an inducible cell model of Huntington's disease. Hum Mol Genet 2001;10:1829-45.

17 Cummings CJ, Mancini MA, Antalffy B, DeFranco DB, Orr HT, Zoghbi HY. Chaperone suppression of aggregation and altered subcellular proteasome localization imply protein misfolding in SCA1. Nat Genet 1998;19:148-54.

18 Chai Y, Koppenhafer SL, Bonini NM, Paulson HL. Analysis of the role of heat shock protein (Hsp) molecular chaperones in polyglutamine disease. J Neurosci 1999; 19:10338-47.

19 Jana NR, Tanaka M, Wang GH, Nukina N. Polyglutamine length-dependent interaction of $\mathrm{Hsp} 40$ and $\mathrm{Hsp} 70$ family chaperones with truncated $\mathrm{N}$-terminal huntingtin: their role in suppression of aggregation and cellular toxicity. Hum Mol Genet 2000:9:2009-18.

20 Kobayashi Y, Kume A, Li M, Doyu M, Hata M, Ohtsuka K, Sobue G. Chaperones $\mathrm{Hsp70}$ and $\mathrm{Hsp} 40$ suppress aggregate formation and apoptosis in cultured neuronal cells expressing truncated androgen receptor protein with expanded polyglutamine tract. J Biol Chem 2000;275:8772-8.

21 Stenoien DL, Cummings CJ, Adams HP, Mancini MG, Patel K, DeMartino GN Marcelli M, Weigel NL, Mancini MA. Polyglutamine-expanded androgen receptors form aggregates that sequester heat shock proteins, proteasome components and SRC-1, and are suppressed by the HDJ-2 chaperone. Hum Mol Genet 1999;8:731-41.

22 Poirier MA, Li H, Macosko J, Cai S, Amzel M, Ross CA. Huntingtin spheroids and protofibrils as precursors in polyglutamine fibrilization. J Biol Chem 2002;277:41032-7.

23 Sanchez I, Mahlke C, Yuan J. Pivotal role of oligomerization in expanded polyglutamine neurodegenerative disorders. Nature 2003;421:373-9.

24 Lee VM. Amyloid binding ligands as Alzheimer's disease therapies. Neurobiol Aging 2002;23:1039-42.

25 Forloni G, Colombo L, Girola L, Tagliavini F, Salmona M. Anti-amyloidogenic activity of tetracyclines: studies in vitro. FEBS Lett 2001;487:404-7.

26 Krause S, Fakan S, Weis K, Wahle E. Immunodetection of poly(A)-binding protein II in the cell nucleus. Exp Cell Res 1994;214:75-82.

27 Abu-Baker A, Messaed C, Laganiere J, Gaspar C, Brais B, Rouleau GA. Involvement of the ubiquitin-proteasome pathway and molecular chaperones in oculopharyngeal muscular dystrophy (OPMD). Hum Mol Genet 2003; 12:2609-23.

28 Saleh A, Srinivasula SM, Balkir L, Robbins PD, Alnemri ES. Negative regulation of the Apaf-1 apoptosome by Hsp70. Nat Cell Biol 2000;2:476-83.

29 Beere HM, Wolf BB, Cain K, Mosser DD, Mahboubi A, Kuwana T, Tailor P, Morimoto RI, Cohen GM, Green DR. Heat-shock protein 70 inhibits apoptosis by preventing recruitment of procaspase- 9 to the Apaf-1 apoptosome. Nat Cell Biol 2000;2:469-75.

30 Smith DL, Woodman B, Mahal A, Sathasivam K, Ghazi-Noori S, Lowden PA, Bates GP, Hockly E. Minocycline and doxycycline are not beneficial in a model of Huntington's disease. Ann Neurol 2003;54:186-96.

31 Chen M, Ona VO, Li M, Ferrante RJ, Fink KB, Zhu S, Bian J, Guo L, Farrell LA, Hersch SM, Hobbs W, Vonsattel JP, Cha JH, Friedlander RM. Minocycline inhibits caspase-1 and caspase- 3 expression and delays mortality in a transgenic mouse model of Huntington disease. Nat Med 2000;6:797-801.

32 Roterman I, Krol M, Nowak M, Konieczny L, Rybarska J, Stopa B, Piekarska B, Zemanek $G$. Why Congo red binding is specific for amyloid proteins-model studies and a computer analysis approach. Med Sci Monit 2001;7:771-84.

33 Blondelle SE, Forood B, Houghten RA, Perez-Paya E. Polyalanine-based peptides as models for self-associated beta-pleated-sheet complexes. Biochemistry 1997;36:8393-400.

\section{CORRECTION}

Giusti RM, Rutter JL, Duray PH, et al. J Med Genet 2003;40:787-792. During the production process errors were introduced into Table 1 of this paper. The odds ratio value for the BRCAl 5382insC mutation in the WAS + MECC studies should read 0.95 . The $95 \%$ CI for the BRCA2 6174delT and the total positive frequency should read 0.89-4.56 and $1.18-3.65$, respectively. 